\title{
Effectiveness of early quadriceps exercises after anterior cruciate ligament reconstruction
}

\author{
Candice Permall (BSc Physiotherapy) \\ Alet van Wyk (BSc Physiotherapy) \\ Anneen van Zyl (BSc Physiotherapy) \\ Tihanna Vorster (BSc Physiotherapy) \\ Quinette Louw (BSc, MASP, PhD) \\ Division of Physiotherapy, Stellenbosch University, South Africa
}

\begin{abstract}
Objective. To systematically review the published information regarding the effectiveness and safety of early postoperative quadriceps muscle exercise training on pain, joint laxity, function and range of motion in postoperative anterior cruciate ligament $(A C L)$ reconstruction adult patients.

Data sources. Five databases (CINAHL, PEDro, Pubmed, Science Direct and the Cochrane Library) were searched for studies published from January 1990 to May 2007.

Study selection. Publications describing research into the effectiveness of early quadriceps exercises after ACL reconstruction were included. A total of three eligible articles met the inclusion criteria.

Data extraction. A review of the three eligible studies was undertaken to describe the key study components. The PEDro Scale was used to determine the methodological quality of the selected trials and the level of evidence of all the eligible studies was categorised according to the evidence hierarchy by Lloyd-Smith. ${ }^{24}$ Relevant data were extracted by the two reviewer groups to reduce bias.

Data synthesis. Due to study heterogeneity a meta-analysis could not be conducted. Effect sizes were calculated provided that sufficient data were provided. Outcome measures included range of motion (ROM), functional performance, pain
\end{abstract}

\section{CORRESPONDENCE:}

Quinette Louw

Division of Physiotherapy

Stellenbosch University

P O Box 19063

Tygerberg

7505

South Africa

Tel: 27219389300

Fax 27219311252

E-mail: qalouw@sun.ac.za and knee laxity. The methodological quality of the studies did not vary considerably across the studies and the average PEDro score was $66 \%$. Marginal significant differences were noted in knee ROM at 1 month postoperatively, pain day 1 postoperatively, knee laxity and subjective evaluation of function at 6 months postoperatively.

Conclusion. Early quadriceps exercises can be performed safely in the first 2 postoperative weeks, but clinically significant gains in ROM, function, pain and knee laxity were not evident. Further research should include standardised interventions, measurement time frames and outcome measurement tools to allow for a meta- analysis to be conducted.

\section{Introduction}

Anterior cruciate ligament $(\mathrm{ACL})$ rupture is one of the most common debilitating knee injuries. ${ }^{36}$ This knee injury is commonly sustained by individuals participating in sporting activities that require pivoting, jumping and decelerating actions. ${ }^{6,36}$ Immediately after an $\mathrm{ACL}$ injury, the athlete experiences significant functional limitations due to significant swelling and pain. ${ }^{14,37}$ Athletes are generally eager to return to their usual level of sporting activity and often also experience psychological distress as the recovery process usually lasts for a few months. ${ }^{18,37}$

The management of an ACL injury may be conservative or surgical. ${ }^{16,18}$ However, surgical reconstruction is currently the most common approach in the management of ACL injuries. ${ }^{8,22,41}$ The functional outcome after surgical reconstruction appears to be more favourable compared with that of non-surgical management approaches. ${ }^{1}$ However, despite advances in ACL repair after reconstructive surgery to optimise the mechanical stability, functional instability of the knee may still be evident in the post-surgery stage. ${ }^{2}$

Physical rehabilitation plays an important role in retraining functional stability of the knee joint after knee surgery. ${ }^{18}$ It has also been found that functional rehabilitation was the most important positive prognostic factor for predicting early return to sport. ${ }^{18}$ Physiotherapists have the opportunity to select the most appropriate rehabilitation protocol for the specific ACL-injured individual from a range of rehabilitation approaches. Prolific 
research has been published on rehabilitation protocols after ACL reconstruction. ${ }^{34}$ Published research in the 1980 s focused on the effectiveness of electrical stimulation of the quadriceps muscle in the acute postoperative stage to decrease the effect of muscle atrophy and weakness. ${ }^{28}$ More recently, the focus of published research has been on accelerated versus non-accelerated rehabilitation programmes, as well as open-kinematic chain versus closed-kinematic chain exercises in early rehabilitation after ACL reconstruction. ${ }^{5,9}$ Anecdotally, it is proposed that accelerated rehabilitation programmes that allow early range of motion (ROM), immediate weight-bearing and early return to previous functional level should be advocated as best practice. However, these recommendations for best practice are often based on clinical opinion and not on research evidence. ${ }^{9}$ Clinical decision-making regarding the most appropriate exercises should be based on research evidence. ${ }^{9}$

Appropriate neuromuscular function of the quadriceps muscle group is required during static and dynamic function of the lower limb. ${ }^{27}$ Inadequate quadriceps muscle strength may result in functional instability of the knee joint after ACL injury or reconstruction. ${ }^{21}$ Quadriceps muscle weakness is a common sequel after ACL surgery. ${ }^{40}$ Quadriceps dyskinesia and weakness follow $A C L$ injury due to neural and physiological changes such as the loss of ACL mechanoreceptor feedback, abnormal gamma loop function of the quadriceps femoris muscle, atrophy of muscle fibres and neural activation deficits. ${ }^{17,30}$

To prevent weakness of the quadriceps muscle and knee extension lag, physiotherapists commonly prescribe quadriceps exercises after ACL reconstruction as early as possible during the inpatient rehabilitation phase. ${ }^{34}$ However, given the high costs of surgery and lengthy rehabilitation, the costeffectiveness of prescribing early quadriceps exercises has been questioned. ${ }^{34}$ Furthermore, the safety of early quadriceps muscle strengthening after ACL reconstruction may also be of concern as postoperative anterior-posterior laxity could compromise the integrity of the ACL. ${ }^{15}$ Quadriceps muscle contraction produces a rotatory component around the knee joint axis, and also creates a translatory component that causes an anterior shear of the tibia on the femur. ${ }^{20}$ The ACL creates an antagonistic pull to resist this anterior shear produced by the quadriceps contraction and by doing so, provides stability to the knee. ${ }^{20}$ There is thus strain on the ACL during active quadriceps muscle contraction, mainly in the last 45 degrees of extension, which could compromise the integrity of the graft. ${ }^{30}$

The aim of this review was therefore to systematically appraise the effect of early postoperative quadriceps exercise training on pain, joint laxity, ROM and function, compared with a rehabilitation programme not allowing early quadriceps exercises or restricting quadriceps exercise training to only isometric quadriceps contractions in postoperative $\mathrm{ACL}$ reconstruction patients aged between 17 and 44 years.

\section{Methodology}

The specific objectives of the review were to:

- describe the type of quadriceps exercises implemented in eligible randomised controlled trials
- describe the outcome measures used to assess pain, knee joint laxity, ROM and function after ACL reconstruction

- assess the effectiveness and safety of early postoperative quadriceps exercise training on pain, joint laxity, function and ROM when compared with a rehabilitation programme not allowing early quadriceps exercises or restricting quadriceps exercise training to only isometric quadriceps contraction in postoperative $\mathrm{ACL}$ reconstruction patients aged between 17 and 44 years.

The following definitions were used in this review:

- Early quadriceps exercises: Any active lower limb activity aimed specifically at contraction of the quadriceps to achieve full-range knee extension and performed within the first 2 weeks or in the in-patient phase after ACL reconstructive surgery. ${ }^{32,34,38}$

- ACL reconstruction: The surgical repair of the ACL after complete $A C L$ rupture or recurrent ligament injury. ${ }^{10}$ All types of grafts including bone-patellar tendon-bone, bone-tendonbone, semitendinosus-hamstring and semitendinosus-gracilis grafts were included in this review. ${ }^{35}$

- Knee instability: The lack of physiological anteriorposterior (A-P) and rotational steadiness of the knee joint. ${ }^{42}$ Manual clinical tests to evaluate knee instability include the anterior draw, Lachman's and pivot shift tests. ${ }^{33}$ The KT-1000 arthrometer is a popular instrument for measuring knee instability. ${ }^{33}$

- Function: The ability to safely perform weight-bearing activities including gait, stair climbing and pre-injury function. ${ }^{21,38}$ Shaw et al. described a number of tests used to assess function, including the single and triple hop tests, timed hop tests, vertical jump tests, stairs hopple test and figure eight running. ${ }^{33}$

- Pain: The experience of knee pain as measured with validated pain scales such as the Visual Analogue Scale (VAS). ${ }^{4}$

- Range of motion (ROM): The amount of motion, measured in degrees, available to a joint within the anatomic limits of the joint structure. ${ }^{20}$ Active and passive range of flexion and extension of the knee can be assessed objectively with a goniometer. ${ }^{33}$

\section{Search strategy}

Prior to commencing this project, the Cochrane Library and PEDro were searched to ascertain if a similar review had not been published within the past 5 years. The search findings indicated that a similar review had not been published.

Search strategies were developed for the following computerised bibliographical databases: CINAHL, PEDro, Pubmed, Science Direct and the Cochrane Library. These databases were available via the University of Stellenbosch Library and the World Wide Web. All databases from January 1990 to May 2007 were searched. Each search strategy was developed according to the functions of each database group as follows:

- Group 1: Databases where papers are classified according to their medical subject headings (MeSH) and key terms. These databases allow for terms to be combined (PubMed, CINAHL, The Cochrane Library). 
- Group 2: Databases where key terms are used to classify papers. These databases have a limited ability to combine key terms (Science Direct, PEDro).

A detailed search strategy for each of the selected databases was designed. The key search terms were anterior cruciate ligament, ACL, reconstruction, repair, rehabilitation, strengthening, pain, function, exercises. MeSH terms were used in PubMed.

In addition, a secondary search (PEARLing) was conducted by screening the reference lists of all potential full-text articles. To ensure that eligible articles not indexed in the electronic databases were not missed, the authors of the eligible articles were contacted via e-mail.

\section{Eligibility criteria for inclusion}

This review included primary research randomised-controlled clinical trials with an acceptable methodological quality appraisal score of at least 4 out of 11 on the PEDro scale. ${ }^{7}$ Studies reporting on males and females aged between 17 and 44 years, who underwent unilateral $A C L$ reconstruction of either the right or left knee by the use of any type of graft, were considered eligible for this review. The eligible age was determined by skeletal maturity that is present over the age of 16 years. ${ }^{36}$ Articles reporting on patients with common ACL-associated injuries such as medial meniscal injuries were considered eligible since isolated $A C L$ injuries are rare and do not replicate the population of ACL reconstructions generally managed by physiotherapists.

Studies reporting on participants who underwent previous ACL reconstruction on the reconstructed knee, sustained injury to the contralateral knee or presented with any other rheumatological, neurological, cardiovascular or congenital condition that could affect lower-limb function and result in disability, were excluded from this review as they would not reflect the true outcome of this specific intervention. ${ }^{36}$

The interventions of the studies also determined eligibility. Studies that included one treatment group who performed early quadriceps exercises within the first 2 weeks postoperatively and a control group who underwent rehabilitation excluding early quadriceps exercise training or only allowing early isometric quadriceps exercise training were considered eligible for this review.

Eligible studies reporting on the following outcome measures were considered for this review:

- Active range of flexion and extension of the knee as measured with a goniometer. ${ }^{33}$

- Pain experienced as measured with the Visual Analogue Scale or other published validated pain scales. ${ }^{4}$

- Knee stability as measured with the KT-1000 arthrometer or other validated knee-instability scales. ${ }^{33}$

- Lower-limb function as determined by functional tests including the single and triple hop tests, timed hop tests, vertical jump tests, stairs hopple test, figure eight running and other relevant functional tests. ${ }^{33}$

The two reviewer groups screened all hits and selected relevant titles independently. Differences between pairs were discussed until consensus was reached and the fifth author was consulted to resolve any disagreements.

\section{Assessment of methodological quality}

In order to determine the internal validity of the eligible trials, the PEDro Scale was used (Table I). The PEDro scale is commonly used in research to critically evaluate randomised controlled trials. ${ }^{25}$

\section{Evidence hierarchy}

The level of evidence of all the studies included in this review was evaluated using the evidence hierarchy by Lloyd-Smith. ${ }^{24}$

- 1a: Meta analysis of randomised controlled trials

- 1b: One individual randomised controlled study

- 2a: One well-designed, non-randomised controlled study

- 2b: Well-designed quasi-experimental study

- 3: Non-experimental descriptive studies - comparative/case studies

- 4: Respectable opinion.

Study designs fulfilling the ' $1 b$ ' criteria were considered eligible for inclusion.

\section{Data extraction}

The four reviewers were divided into two reviewer groups to extract the data. This was done independently by each of the two reviewer groups. The fifth author was consulted to resolve any discrepancies between the two reviewer groups. The following information was extracted: publication date, authors, journal, study design, setting, PEDro score, aim, description of participants, type of grafts, author's conclusion, clinical relevance, number of participants, description of interventions and outcome measures used.

\section{Data synthesis}

The three eligible studies presented heterogeneity with respect to the exercise interventions performed, the outcome measurement tools used and the time frames of measurement. Therefore it was not possible to perform a meta-analysis.

The effect size was calculated with the available data where significant differences between groups were reported by the authors. The effect size represents the clinical magnitude of difference between groups. ${ }^{29}$ A greater observed effect represents a larger significant difference. ${ }^{29}$ One of the eligible studies, Shaw et al. reported sufficient data (mean and SD) to calculate the effect size. ${ }^{34}$

\section{Results}

\section{Search results}

The results of the search strategy are presented in a flow chart (Fig. 1). Three articles were considered eligible - from Australia, Sweden and Germany. ${ }^{11,15,34}$

\section{Evidence hierarchy}

The three selected studies were RCTs, representing level ' $1 b$ ' evidence according to the grading system of Lloyd-Smith. ${ }^{24}$

\section{Methodological quality appraisal}

There was $100 \%$ agreement between the two reviewer groups regarding the methodological score. The average methodological quality score was $66 \%$ (Table I). 


\section{TABLE I. Summary of the PEDro scores}

PEDro criteria

Eligibility criteria were specified

Subjects were randomly allocated to groups

Allocation was concealed

Groups were similar at baseline regarding important prognostic indicators

Blinding of all subjects

Blinding of all therapists who administered the therapy

Blinding of all assessors who measured at least one key outcome

Measures of at least one key outcome were obtained from more than

$85 \%$ of the subjects initially allocated to groups

Subjects for whom outcome measures were available received the

treatment or control condition, if not, data for at least one key

outcome was analysed by 'intention to treat'

Results of between-group statistical comparisons are reported for at least one key outcome

Provided both point measures and measures of variability for at least one key outcome

$$
\text { Total score }
$$

$\begin{array}{llc}\begin{array}{l}\text { Shaw } \\ \text { et al. }\end{array} & \begin{array}{l}\text { Isberg } \\ \text { et al. }\end{array} & \begin{array}{c}\text { Friemert } \\ \text { et al. }\end{array} \\ \sqrt{ } & - & \sqrt{ } \\ \sqrt{ } & \sqrt{ } & \sqrt{ } \\ \sqrt{ } & \sqrt{ } & - \\ - & \sqrt{ } & \sqrt{ } \\ - & - & - \\ - & - & - \\ \sqrt{ } & - & - \\ \sqrt{ } & \sqrt{ } & \sqrt{ } \\ \sqrt{ } & \sqrt{ } & \sqrt{ } \\ & & \\ \sqrt{ } & \sqrt{ } & \sqrt{ } \\ \sqrt{ } & 7 / 11 & \sqrt{ }\end{array}$

\section{TABLE II. Sample descriptions}

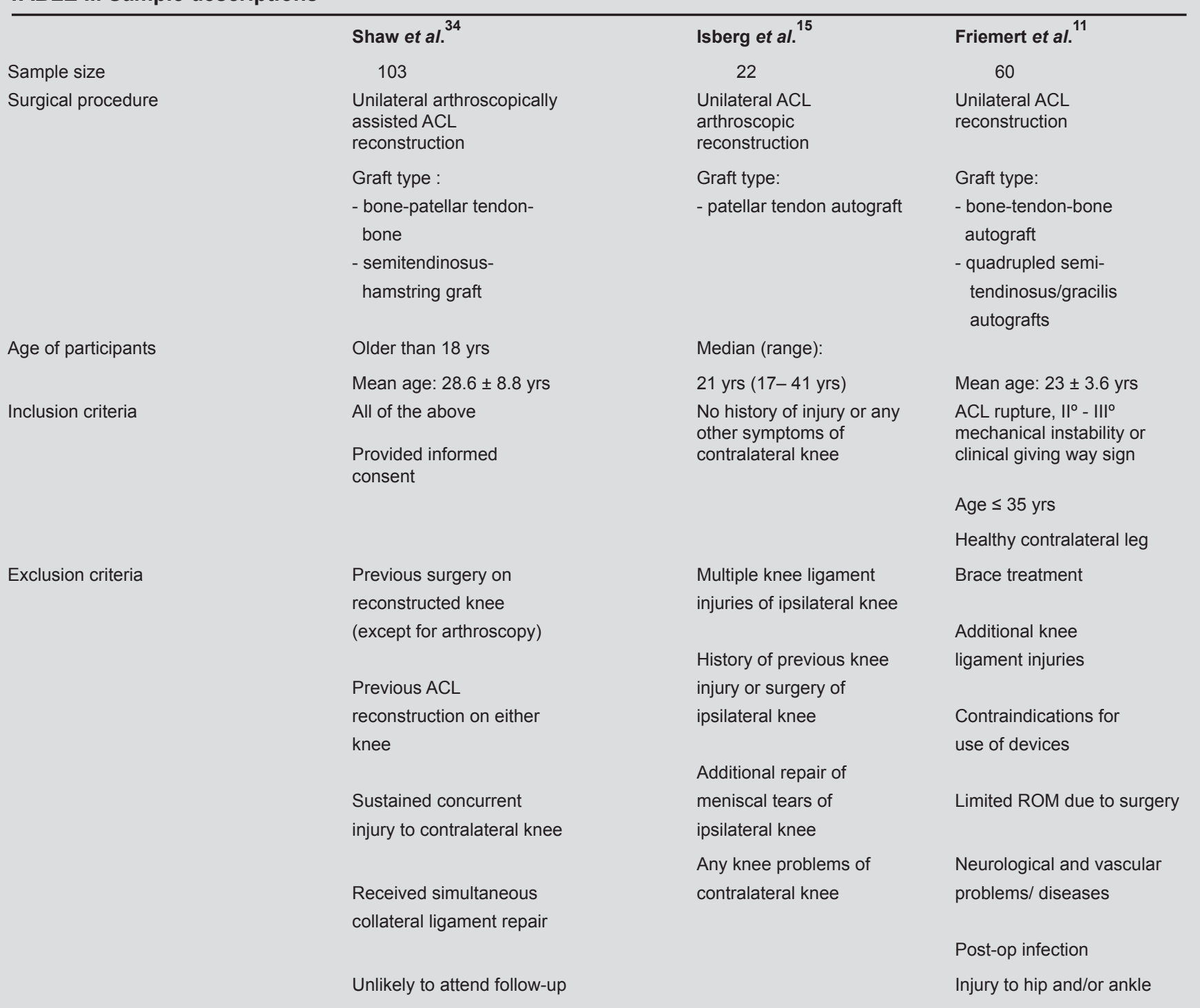




\begin{tabular}{|c|c|c|c|c|}
\hline & $\begin{array}{l}\text { Intervention } \\
\text { group }\end{array}$ & Control group & $\begin{array}{l}\text { Exercises } \\
\text { performed by both } \\
\text { groups }\end{array}$ & $\begin{array}{l}\text { Duration of } \\
\text { interventions }\end{array}$ \\
\hline Shaw et al. ${ }^{34}$ & $\begin{array}{l}\text { Specific } \\
\text { quadriceps } \\
\text { exercises : } \\
\text { - Straight leg } \\
\text { raises } \\
\text { - Isometric } \\
\text { quadriceps } \\
\text { contractions } \\
(10 \times 3 \text { daily })\end{array}$ & $\begin{array}{l}\text { No specific } \\
\text { quadriceps } \\
\text { exercises }\end{array}$ & $\begin{array}{l}\text { General exercise } \\
\text { programme } \\
\text { consisting of: } \\
\text { - Foot and ankle } \\
\text { exercises } \\
\text { - Active assisted } \\
\text { knee flexion } \\
\text { - Calf stretches } \\
\text { - Passive knee } \\
\text { extension } \\
\text { - Standing posture } \\
\text { - Gait education } \\
\text { - Passive knee } \\
\text { extension with } \\
\text { weight }\end{array}$ & $\begin{array}{l}\text { First } 2 \\
\text { postoperative } \\
\text { weeks }\end{array}$ \\
\hline Isberg et al. ${ }^{15}$ & $\begin{array}{l}\text { Full active and } \\
\text { passive knee } \\
\text { extension between } \\
30^{\circ} \text { and }-10^{\circ} \text { was } \\
\text { allowed, } \\
\text { immediately } \\
\text { postoperatively }\end{array}$ & $\begin{array}{l}\text { Full active and } \\
\text { passive knee } \\
\text { extension between } \\
30^{\circ} \text { and }-10^{\circ} \text { was } \\
\text { not allowed, } \\
\text { immediately } \\
\text { postoperatively, } \\
\text { thus restricting } \\
\text { active and passive } \\
\text { knee extension }\end{array}$ & $\begin{array}{l}\text { Rehabilitation brace } \\
\text { and postoperative } \\
\text { rehabilitation } \\
\text { programme }\end{array}$ & $\begin{array}{l}\text { First } 4 \\
\text { postoperative } \\
\text { weeks }\end{array}$ \\
\hline Friemert et al. ${ }^{11}$ & $\begin{array}{l}\text { Continuous active } \\
\text { motion (CAM) of } \\
\text { knee flexion and } \\
\text { extension }\end{array}$ & $\begin{array}{l}\text { Continuous } \\
\text { passive motion } \\
\text { (CPM) of knee } \\
\text { flexion and } \\
\text { extension }\end{array}$ & $\begin{array}{l}\text { Postoperative } \\
\text { rehabilitation } \\
\text { programme, including } \\
\text { isometric } \\
\text { strengthening } \\
\text { exercises and partial } \\
\text { weight-bearing }\end{array}$ & $\begin{array}{l}\text { Day } 1 \text { - } 7 \\
\text { postoperative }\end{array}$ \\
\hline
\end{tabular}

\begin{tabular}{|c|c|c|c|}
\hline Databases & Initial hits & $\begin{array}{l}\text { Accepted titles/ } \\
\text { abstracts }\end{array}$ & Duplic \\
\hline CINAHL & $N=52$ & 5 & \\
\hline PEDRO & $N=350$ & 20 & \\
\hline PUBMED & $N=298$ & 21 & \\
\hline SCIENCE DIRECT & $N=247$ & 15 & \\
\hline \multirow[t]{2}{*}{$\begin{array}{l}\text { THE COCHARANE } \\
\text { COLLABORATION }\end{array}$} & $N=542$ & 59 & \\
\hline & $N=1489$ & 119 & \\
\hline \multirow{3}{*}{\multicolumn{2}{|c|}{\begin{tabular}{|l|} 
Excluded article titles \\
$N=1369$ \\
(initial hits - accepted \\
titles) \\
Articles excluded as the \\
titles were not relevant to \\
the research question
\end{tabular}}} & \multicolumn{2}{|c|}{$\begin{array}{l}\text { Potentially eligible study } \\
\text { tittes/abstracts: } \\
N=119\end{array}$} \\
\hline & & \multirow{2}{*}{\multicolumn{2}{|c|}{$\begin{array}{l}\text { Excluding abstracts and } \\
\text { their duplicates: } \\
\text { Abstracts were excluded } \\
\text { because they either did } \\
\text { not meet inclusion/ } \\
\text { exclusion criteria or they } \\
\text { were duplicates }\end{array}$}} \\
\hline $\begin{array}{l}\text { Eligible articles: } \\
N=3\end{array}$ & & & \\
\hline
\end{tabular}

Fig. 1. Results of the search strategy.

\section{Description of study samples}

Information regarding participants in each study according to the sample size, age, surgical procedure and inclusion and exclusion criteria was tabulated (Table II). Sample sizes differed across the three studies and the means sample size was 61 . The mean age of the samples in the three studies was comparable and none of the studies included participants older than 41 years of age. According to the inclusion and exclusion criteria, all three studies excluded contralateral knee injuries or multiple ligament injuries of the reconstructed knee. A history of previous knee injury or surgery of the reconstructed knee was excluded for Shaw et al. and Isberg et al. ${ }^{15,34}$

\section{Description of exercise interventions}

The exercise programmes performed by the intervention and control group for each of the three studies are described in Table III. The intervention groups of all three studies performed early quadriceps exercises within the first 2 postoperative weeks. The control groups did not perform early quadriceps exercises except for Friemert et al., where only early isometric strengthening exercises were allowed in the first postoperative week. ${ }^{11}$

\section{Description of the outcome measures}

The outcomes measures and measurement time frames utilised are summarised in Table IV. Range of motion was the only outcome measure utilised in three studies.

\section{Effectiveness of early quadriceps exercises}

The effectiveness of early quadriceps exercise training is presented according to each outcome measure. 


\section{Range of motion}

Shaw et al. measured three ranges over the 6-month follow-up period, namely: active knee flexion, active knee extension and passive knee extension relative to neutral, but the measurement tool was not mentioned. ${ }^{34}$ They used mean differences and $95 \%$ confidence intervals to determine significant differences between the intervention and control groups. ${ }^{34}$ Significant between-group differences (Table $\mathrm{V}$ ) in active knee flexion and extension 1 month postoperatively were reported. However, it is notable that the lower $95 \%$ confidence intervals for both active knee flexion and extension are only marginally significant as they are close to zero. The effect size for knee flexion was 0.44 (medium effect) and 0.48 (medium effect) for extension 1 month postoperatively.

The effect size for active knee flexion in the study by Friemert et al. was 0.15 (small effect) at 7 days postoperatively. ${ }^{11}$

\section{Functional performance}

Shaw et al. objectively evaluated function by means of the functional hop tests consisting of the single-leg-hop and the tripleleg-hop tests (Table VI). ${ }^{34}$ Measurements are given as a percentage difference of the reconstructed leg strength relative to the non-operative leg by Shaw et al. and Isberg et al. ${ }^{15,34}$ Shaw et al. assessed function 6 months postoperatively and confidence intervals span zero, indicating no between-group significant differences. ${ }^{34}$

Isberg et al. objectively evaluated function pre-operatively, at 6 months postoperatively and at 2 years follow-up by means of the single-leg-hop test. ${ }^{15}$ No significant differences between the groups were found. The third study by Friemert et al. did not report on function objectively. ${ }^{11}$

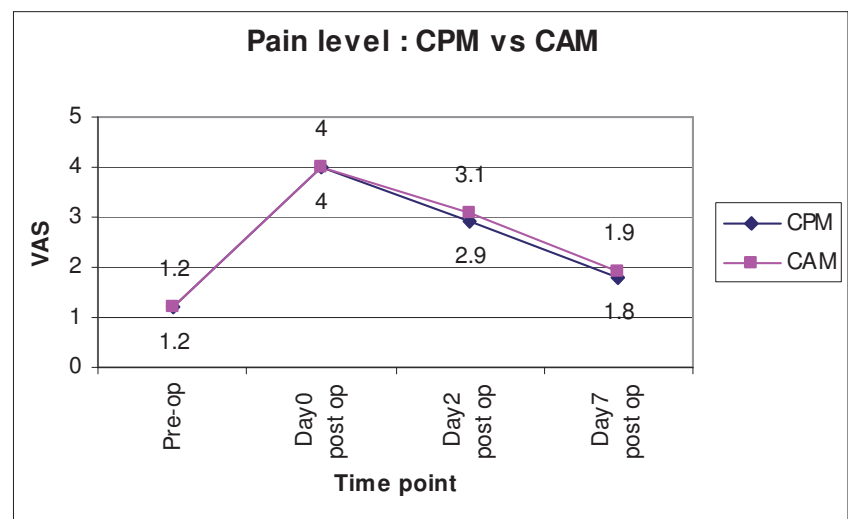

Fig. 2. Pain as measured by VAS for Friemert et al. ${ }^{11}$

Function was subjectively evaluated using outcome measurement scales in two of the studies. ${ }^{15,34}$ The Lysholm score, Tegner score and International Knee Documentation Committee (IKDC) evaluation system were used by Isberg et al. ${ }^{15}$ These measurements were taken preoperatively and at 2year follow-up. Negligible differences were found between the groups at 2 years.

Shaw et al. used the Cincinnati Knee Rating System (CKRS) for subjective assessment of function. ${ }^{34}$ The CKRS is a unique rating system that consists of several subdivisions that provide questionnaires for symptoms, function and occupation. ${ }^{33}$ The

\section{TABLE IV. Description of outcome measures}

\begin{tabular}{|c|c|c|c|c|c|c|c|c|c|c|c|c|}
\hline \multirow{2}{*}{ Outcome } & \multirow{2}{*}{ Study } & \multirow{2}{*}{$\begin{array}{l}\text { Outcome } \\
\text { measure }\end{array}$} & \multicolumn{10}{|c|}{ Time of measurement } \\
\hline & & & Pre-op & Day 0 & Day 1 & Day 2 & Day 7 & 2 weeks & 1 mnth & 3 mnths & 6 mnths & 2-yrs \\
\hline \multirow[t]{3}{*}{ ROM } & $\begin{array}{l}\text { Shaw }_{34} \\
\text { et al. }\end{array}$ & $\begin{array}{l}\text { Not explicitly } \\
\text { stated }\end{array}$ & & & $\sqrt{ }$ & & & $\sqrt{ }$ & $\sqrt{ }$ & $\sqrt{ }$ & $\sqrt{ }$ & \\
\hline & $\begin{array}{l}\text { Isberg } \\
\text { et al. }{ }^{15}\end{array}$ & $\begin{array}{l}\text { Standard } \\
\text { handheld } \\
\text { goniometer }\end{array}$ & $\sqrt{ }$ & & & & & & & & $\sqrt{ }$ & $\sqrt{ }$ \\
\hline & $\begin{array}{l}\text { Friemert } \\
\text { et al. }{ }^{11}\end{array}$ & $\begin{array}{l}\text { Not explicitly } \\
\text { stated }\end{array}$ & $\sqrt{ }$ & & & & $\checkmark$ & & & & & \\
\hline \multirow[t]{2}{*}{ Function } & $\begin{array}{l}\text { Shaw } \\
\text { et al. }{ }^{34}\end{array}$ & $\begin{array}{l}\text { Single-hop- } \\
\text { test } \\
\text { Triple-hop- } \\
\text { test }\end{array}$ & & & & & & & & & $\sqrt{ }$ & \\
\hline & $\begin{array}{l}\text { Isberg } \\
\text { et al. }{ }^{15}\end{array}$ & $\begin{array}{l}\text { Single-hop- } \\
\text { test }\end{array}$ & $\sqrt{ }$ & & & & & & & & $\sqrt{ }$ & $\sqrt{ }$ \\
\hline \multirow[t]{2}{*}{ Pain } & $\begin{array}{l}\text { Shaw } \\
\text { et al. }\end{array}$ & $10 \mathrm{~cm}$ VAS & & & $\sqrt{ }$ & & & $\sqrt{ }$ & $\sqrt{ }$ & $\sqrt{ }$ & $\sqrt{ }$ & \\
\hline & $\begin{array}{l}\text { Friemert } \\
\text { et al. }\end{array}$ & $10 \mathrm{~cm}$ VAS & $\sqrt{ }$ & $\sqrt{ }$ & & $\sqrt{ }$ & $\sqrt{ }$ & & & & & \\
\hline \multirow[t]{2}{*}{$\begin{array}{l}\text { Knee } \\
\text { laxity }\end{array}$} & $\begin{array}{l}\text { Shaw } \\
\text { et al. }{ }^{34}\end{array}$ & KT-1000 & & & & & & & & $\checkmark$ & $\sqrt{ }$ & \\
\hline & $\begin{array}{l}\text { Isberg } \\
\text { et al. }{ }^{15}\end{array}$ & $\begin{array}{l}\text { KT-1000 } \\
\text { RSA }\end{array}$ & $\sqrt{ }$ & & & & & & & & $\sqrt{ }$ & $\sqrt{ }$ \\
\hline
\end{tabular}




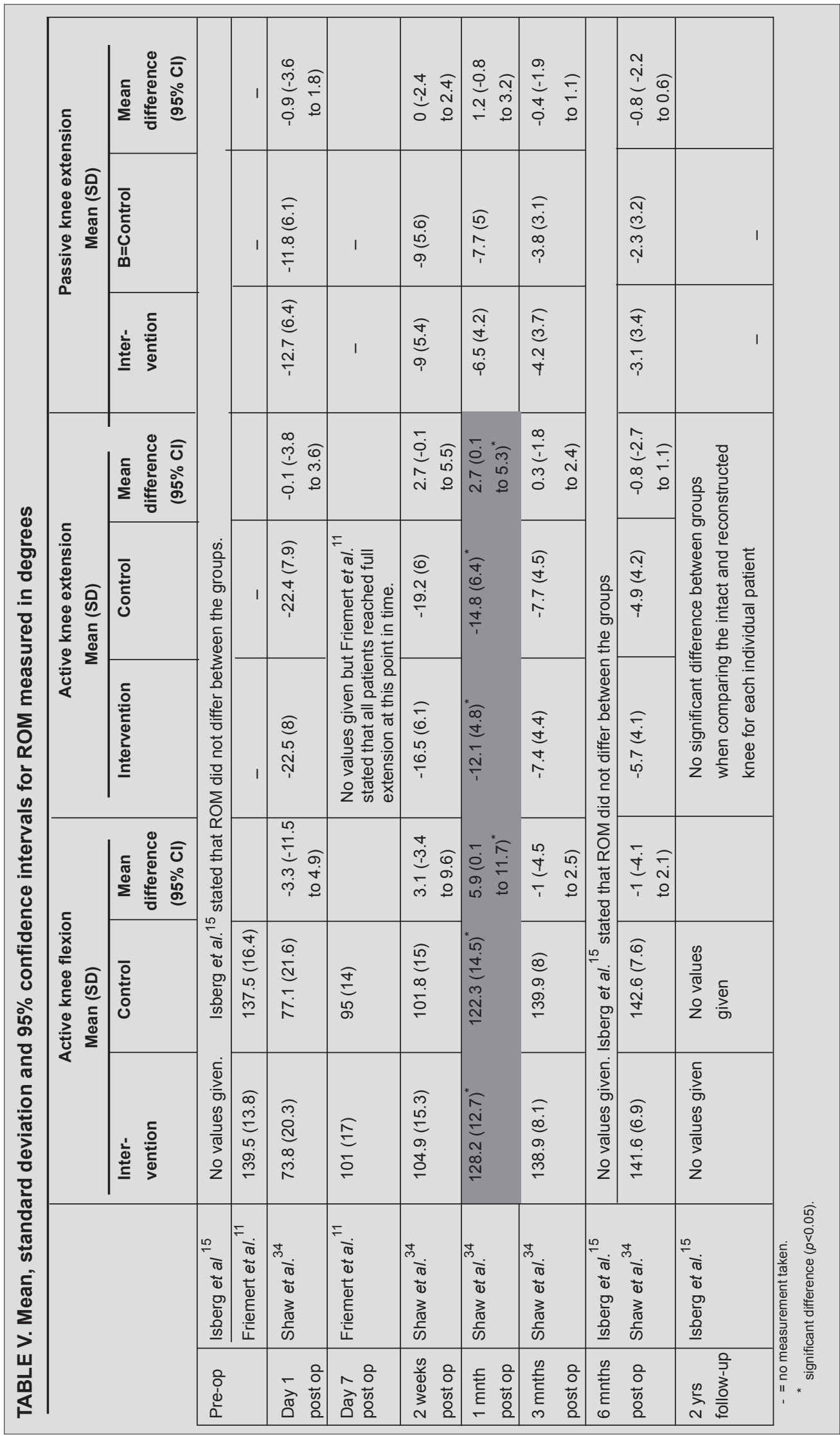

measures were taken at 1, 3 and 6 months postoperatively. At 6 months postoperatively, statistically significant differences between the groups were demonstrated for the subdivision 'Problems with Sport'. The intervention group had a higher (more favourable) score than the control group for the 'Problems with Sport' category (Table VII). However, the $95 \% \mathrm{Cl}$ spans 0 and the effect size we calculated were 0.33 , indicating that the effect of the early quadriceps exercises was small.

\section{Pain assessment}

According to Shaw et al. there was no statistically significant difference between the groups for pain perception at any follow-up intervals (Table VIII). ${ }^{34}$ However, in the quadriceps exercise group, significantly greater pain with exercise performance was measured on the first postoperative day.

Findings of the studies conducted by Friemert et al. did not demonstrate significant differences in preoperative pain measurements on the operative day and on the second and seventh day postoperatively (Fig. 2). ${ }^{11}$ Isberg et al. did not report on pain as an outcome measure. $^{15}$

Shaw et al. further evaluated pain by means of die CKRS evaluation system. ${ }^{34}$ Six months postoperatively the intervention group reported significantly higher (more favourable) results for pain calculated under the CKRS subdivision 'Symptoms' (Table IX). However, the lower confidence interval is marginally significant (0.2). The effect size calculated as 0.62 , indicating that the early quadriceps exercises had a moderate on pain perception.

\section{Knee laxity}

Shaw et al. measured A-P laxity by means of the KT1000 using a 15-pound, 20pound and maximal manual test force. ${ }^{34}$ Measurements, presented in Table $\mathrm{X}$, were taken 3 and 6 months postoperatively. A-P side-to-side differences of greater than 3 $\mathrm{mm}$ or greater than $5 \mathrm{~mm}$ were used as cut-off points during testing as these were seen as indications of abnormal laxity. For each test force, Shaw et al. retrieved the number of abnormally 


\begin{tabular}{|c|c|c|c|c|c|c|c|}
\hline & & \multicolumn{3}{|c|}{ Single-leg-hop } & \multicolumn{3}{|c|}{ Triple-leg-hop } \\
\hline & & Intervention & Control & $\begin{array}{c}\text { Mean } \\
\text { difference } \\
(95 \% \mathrm{Cl})\end{array}$ & Intervention & Control & $\begin{array}{l}\text { Mean } \\
\text { difference } \\
(95 \% \mathrm{Cl})\end{array}$ \\
\hline $\begin{array}{l}\text { Pre- } \\
\text { operative }\end{array}$ & $\begin{array}{l}\text { Isberg } \\
\text { et al. } 15 \\
\text { Median } \\
\text { (range) }\end{array}$ & $\begin{array}{l}82 \\
(0-96)\end{array}$ & $\begin{array}{l}80 \\
(0-96)\end{array}$ & & $\begin{array}{c}\text { Not } \\
\text { measured }\end{array}$ & $\begin{array}{c}\text { Not } \\
\text { measured }\end{array}$ & \\
\hline 6 mnths & $\begin{array}{l}\text { Shaw } \\
\text { et al. }{ }^{34} \\
\text { Mean (SD) }\end{array}$ & $83.8(10.1)$ & $81.7(12.7)$ & 2.1 (-2.8 to 7$)$ & $83.7(11.4)$ & $81.8(13.6)$ & $\begin{array}{c}1.9 \\
(-3.5 \text { to } 7.3)\end{array}$ \\
\hline 24 mnths & $\begin{array}{l}\text { Isberg } \\
\text { et al. } 15 \\
\text { Median } \\
\text { (range) }\end{array}$ & $\begin{array}{l}97 \\
(86-100)\end{array}$ & $\begin{array}{l}96 \\
(85-100)\end{array}$ & & Not measured & Not measured & \\
\hline
\end{tabular}

\begin{tabular}{|c|c|c|c|}
\hline & $\begin{array}{l}\text { Intervention } \\
\text { Mean (SD) }\end{array}$ & $\begin{array}{l}\text { Control } \\
\text { Mean (SD) }\end{array}$ & $\begin{array}{l}\text { Mean } \\
\text { difference } \\
(95 \% \mathrm{Cl})\end{array}$ \\
\hline $\begin{array}{l}1 \text { mnth } \\
3.4) \\
\text { post op }\end{array}$ & $40.2(11.6)$ & $41.6(11.9)$ & $-1.4 \quad(-6.2$ to \\
\hline $\begin{array}{l}3 \text { mnths } \\
\text { post op }\end{array}$ & $55.2(12.5)$ & $51.2(12.4)$ & $4(-1.2$ to 9.2$)$ \\
\hline $\begin{array}{l}6 \text { mnths } \\
\text { post op }\end{array}$ & $66.4(14.4)^{*}$ & $61.6(15.2)^{*}$ & $4.8(-1.4 \text { to } 11)^{*}$ \\
\hline
\end{tabular}

lax knees and compared this with the number of subjects measured. ${ }^{34}$ The total number of subjects presenting with lax knees were calculated with the available data. The control group demonstrated a significantly greater number of subjects with laxity at each test force 6 months postoperatively. No significant differences were noted 3 months postoperatively.

Isberg et al. used the KT-1000 and radiostereometric analysis (RSA) to evaluate AP laxity preoperatively, 6 months postoperatively and at 2-year follow-up. ${ }^{15}$ No significance between group differences was found at any point of measurement. However, there was a statistically significant reduction in A-P laxity within each group from the pre-operative period until the 2-year follow-up (Table XI).

\section{Discussion}

This paper reports on the effectiveness of early quadriceps exercise after ACL reconstruction and illustrates the sparse literature available to determine the effect of this common physiotherapeutic intervention in this patient intervention. Physiotherapists commonly prescribe static isometric quadriceps exercises early postoperatively, with the aim of restoring neuromuscular function of this muscle as soon as possible. ${ }^{34}$ However, the findings of this paper demonstrate that this usual practice procedure may not apply to all patients and requires reconsideration.

The three eligible papers had common methodological limitations. All three studies have not met the blinding of subjects and therapists criterion. Blinding of therapists and patients in exercise intervention studies is impossible in the majority of trials as the therapists and patients can often differentiate between intervention and placebo exercises for a specific patient population. ${ }^{12}$ Therefore, although there was heterogeneity with respect to sample size, exercise interventions, outcome measurement and data analysis, the methodological quality of the studies is comparable. The methodological quality of the studies was deemed acceptable, evidenced by the critical appraisal findings and therefore the internal validity is considered to be sound. However, since all the trials were conducted at one conveniently selected clinic, the external validity of the studies may be limited. Furthermore, only one of the studies indicated that a sample size calculation was conducted. ${ }^{11}$ The range of the sample sizes was 22-103 participants among the three studies and, according to Shaw et al., were relatively small when compared with the number of $\mathrm{ACL}$ reconstructions performed internationally. ${ }^{34} \mathrm{~A}$ larger sample size is likely to be a more accurate representation of a population and will thus produce more recognisable betweengroup statistically significant differences. ${ }^{29}$ Therefore the power of the remaining two studies has not been indicated, highlighting the limitations with respect to external validity of the findings.

The age of participants ranged from 17 to 41 years in the three selected studies. Adolescents and young adults who are physically active in sports are usually at an increased risk of an ACL injury. ${ }^{24}$ Therefore the age group of subjects represents the high-risk group for ACL injuries. ${ }^{6,246}$ The descriptions of the samples, however, lack specific information about the level and type of sporting activity, which may reflect different levels of motivation to engage in exercise therapy and return to sporting activity. A few months' absence from competition and sport may result in detrimental socio-economic consequences for professional athletes, ${ }^{31}$ who are usually more motivated to commence their rehabilitation process at an earlier stage compared with recreational athletes or sedentary individuals. It may therefore be important to assess the outcome of this early exercise intervention within patient populations with a specific level of sporting activity as the psychological benefits of early rehabilitation may be advantageous in competitive athletes.

The outcomes measurement tools used in the selected studies were valid and reliable. $^{13,19}$ The goniometer, KT1000 , visual analogue and functional hop tests are valid and reliable outcome measures according to the findings of a published systematic review. ${ }^{33}$ According to Isberg et al. the radiostereometric analysis (RSA) is a reliable and valid outcome 


\section{TABLE VIII. Pain as measured with VAS (Shaw et al. ${ }^{34}$ )}

\begin{tabular}{|c|c|c|c|c|c|c|}
\hline & \multicolumn{3}{|c|}{ Pain at rest } & \multicolumn{3}{|c|}{ Pain on performing exercise } \\
\hline & $\begin{array}{l}\text { Intervention } \\
\text { Mean (SD) }\end{array}$ & $\begin{array}{l}\text { Control } \\
\text { Mean (SD) }\end{array}$ & $\begin{array}{c}\text { Mean } \\
\text { difference } \\
(95 \% \mathrm{Cl})\end{array}$ & $\begin{array}{l}\text { Intervention } \\
\text { Mean (SD) }\end{array}$ & $\begin{array}{l}\text { Control } \\
\text { Mean (SD) }\end{array}$ & $\begin{array}{l}\text { Mean } \\
\text { difference } \\
(95 \% \mathrm{Cl})\end{array}$ \\
\hline Day 1 & $3.1(2.2)$ & $2.6(2)$ & $\begin{array}{c}0.5 \\
(-0.3 \text { to } 1.3)\end{array}$ & $6.9(2)^{*}$ & $6(2.1)^{*}$ & $\begin{array}{c}0.9 \\
(0.1 \text { to } 1.7)^{*}\end{array}$ \\
\hline 2 weeks & $2.5(1.7)$ & $2.2(1.9)$ & $\begin{array}{c}0.3 \\
(-0.4 \text { to } 1)\end{array}$ & $5.9(1.9)$ & $5.2(2.1)$ & $\begin{array}{c}0.7 \\
(-0.1 \text { to } 1.5)\end{array}$ \\
\hline 1 month & $0.9(0.8)$ & $0.9(1.1)$ & $\begin{array}{c}0 \\
(-0.4 \text { to } 0.4)\end{array}$ & $3.5(2)$ & $4(2.3)$ & $\begin{array}{c}-0.5 \\
(-1.4 \text { to } 0.4)\end{array}$ \\
\hline 3 months & $0.4(0.7)$ & $0.5(0.7)$ & $\begin{array}{c}-0.1 \\
(-0.4 \text { to } 0.2)\end{array}$ & $3.1(2)$ & $2.8(2.1)$ & $\begin{array}{c}0.3 \\
(-0.6 \text { to } 1.2)\end{array}$ \\
\hline 6 months & $0.3(0.6)$ & $0.3(0.6)$ & $\begin{array}{c}0 \\
(-0.3 \text { to } 0.3)\end{array}$ & $2(1.9)$ & $2.1(1.8)$ & $\begin{array}{c}-0.1 \\
(-0.9 \text { to } 0.7)\end{array}$ \\
\hline
\end{tabular}

\section{TABLE IX. Pain as measured with CKRS} (Shaw et al. ${ }^{34}$ )

\begin{tabular}{|c|c|c|c|}
\hline & $\begin{array}{c}A \\
\text { Mean (SD) }\end{array}$ & $\begin{array}{c}\text { B } \\
\text { Mean (SD) }\end{array}$ & $\begin{array}{l}\text { Mean } \\
\text { difference } \\
(95 \% \mathrm{CI})\end{array}$ \\
\hline $\begin{array}{l}1 \text { mnth } \\
\text { post op }\end{array}$ & $4.9(1)$ & $4.8(1)$ & $\begin{array}{c}0.1 \\
(-0.3 \text { to } 0.5)\end{array}$ \\
\hline $\begin{array}{l}3 \text { mnths } \\
\text { post op }\end{array}$ & $6.1(1.1)$ & $6.2(1.2)$ & $\begin{array}{l}-0.1 \\
(-0.6 \text { to } 0.4)\end{array}$ \\
\hline $\begin{array}{l}6 \text { mnths } \\
\text { post op }\end{array}$ & $7.5(1.2)^{*}$ & $6.8(1.1)^{*}$ & $\begin{array}{l}0.7 \\
(0.2 \text { to } 1.2)\end{array}$ \\
\hline \multicolumn{4}{|c|}{$A=$ intervention group } \\
\hline \multicolumn{4}{|c|}{$B=$ control group } \\
\hline
\end{tabular}

measure. ${ }^{15}$ However, differences in outcome measurement time frames and interpretation did not allow for a meta-analysis of the outcome data. Shaw et al. recommended that key outcome measures should be used at specific time frames postoperatively, in order to optimise the sensitivity of these measuring tools and thus enhance its validity and reliability. ${ }^{33}$ Future research in this field should attempt to identify the most appropriate outcome measurement type and measurement time frames after ACL reconstruction.

Appropriate descriptions of the exercise intervention regimens were presented in the selected studies. This is a positive aspect of the reviewed papers, as a clear description of interventions

\begin{tabular}{|c|c|c|c|c|}
\hline \multicolumn{5}{|c|}{ TABLE X. A-P laxity at 6 months (Shaw et al. ${ }^{34}$ ) } \\
\hline \multicolumn{2}{|l|}{ test force } & $\begin{array}{l}\quad \text { A } \\
\text { Number of } \\
\text { subjects with } \\
\text { laxity }(N)\end{array}$ & \begin{tabular}{l}
\multicolumn{1}{c}{ B } \\
Number of \\
subjects with \\
laxity $(N)$
\end{tabular} & 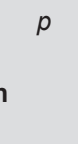 \\
\hline $15 \mathrm{lb}$ & $3 \mathrm{~mm}$ & $3(47)^{*}$ & $12(44)^{*}$ & $0.01^{*}$ \\
\hline $15 \mathrm{lb}$ & $5 \mathrm{~mm}$ & $0(47)$ & $2(44)$ & \\
\hline $20 \mathrm{lb}$ & $3 \mathrm{~mm}$ & $10(47)$ & $13(44)$ & 0.36 \\
\hline $20 \mathrm{lb}$ & $5 \mathrm{~mm}$ & $1(47)$ & $7(44)$ & \\
\hline Max manual & $3 \mathrm{~mm}$ & $17(47)$ & $16(44)$ & 0.99 \\
\hline Max manual & $5 \mathrm{~mm}$ & $1(47)$ & $9(44)$ & \\
\hline \multicolumn{5}{|c|}{$\begin{array}{l}\text { Total number of subjects } \\
\text { presenting with lax knees }\end{array}$} \\
\hline \multicolumn{5}{|c|}{$\begin{array}{l}\text { A-P laxity: An anterior-posterior side-to-side difference of greater than } 3 \mathrm{~mm} \text { or } \\
\text { greater than } 5 \mathrm{~mm} \text { on testing with the } \mathrm{KT}-1000 \text { arthrometer. } \\
\text { * significant difference }(p<0.05)\end{array}$} \\
\hline
\end{tabular}

is often lacking in physiotherapeutic trials. Poor descriptions of the interventions make it difficult or impossible to apply effective interventions based on robust research evidence. The exercise interventions applied in the papers were mostly representative of usual clinical practice. ${ }^{32}$ The findings of this review are therefore relevant to clinicians who prescribe similar exercise regimens as they provide insight into the effect on patient outcomes.

TABLE XI. A-P laxity preoperatively, at 6 months and 24 months follow-up (Isberg et al. ${ }^{15}$ )

\begin{tabular}{|c|c|c|c|c|}
\hline & \multicolumn{2}{|c|}{ RSA } & \multicolumn{2}{|c|}{ KT-1000 } \\
\hline & Intervention & Control & Intervention & Control \\
\hline & Median (range) & Median (range) & Median (range) & Median (range) \\
\hline & in $\mathrm{mm}$ & in $\mathbf{m m}$ & in $\mathbf{m m}$ & in $\mathrm{mm}$ \\
\hline Preoperative & $8.6(2.3-15.4)$ & $7.2(2.2-17.4)$ & $2.0(0-8.0)$ & $4.0(0-10.10)$ \\
\hline 6 mnths & $3.4(0.6-11.5)$ & $3.4(-3.3$ to 7.8$)$ & $0(-3.0$ to 1.5$)$ & 1.5 (0.5 to 4.5$)$ \\
\hline 24 mnths & $2.7(0-10.7)$ & $2.8(-1.8$ to 9.5$)$ & $1.0(-1.5$ to 3.5$)$ & $0.5(-1.0$ to 4.0$)$ \\
\hline Preop v. 24 mnths & $p=0.005$ & $p=0.005$ & $p=0.0096$ & $p=0.004$ \\
\hline
\end{tabular}


Appropriate function of the quadriceps muscle group is important daily and sporting activities. ${ }^{27}$ These review findings indicate that no significant difference in functional performance was noted between the intervention and control group 6 months and 24 months postoperatively. Objective functional performance was not assessed before 6 months due to precautionary limitations related to the surgery. There was no difference between groups with respect to most of the subjective functional scale findings. However, a significant difference for the 'problems with sport category' was reported by Shaw et al., but the effect size indicated that the clinical effect was small. ${ }^{34}$ The finding indicated that the intervention group experienced significantly more pain when exercising, and this may contribute further to inhibit quadriceps muscle contraction. ${ }^{3,34}$ The improvement in muscle function when performing early quadriceps exercises may thus be relatively small and it appears that functional use of the quadriceps muscle performed when the patient's pain experience is tolerable may be appropriate to produce appropriate strength required for function. A clinical recommendation may thus be that pain may need consideration when prescribing these exercises.

Shaw et al. reported that the subjects in the intervention group had marginally better improvement in active knee flexion and extension ROM, but this was limited to 1 month postoperatively. ${ }^{34}$ However, the effect size indicated a medium clinical effect of range of motion at 1 month. According to Milne et al. a minimum of at least $90^{\circ}$ of flexion is required to safely descend stairs and $105^{\circ}$ to rise from a toilet seat. ${ }^{26}$ However, since both groups achieved these functional range requirements, the clinical effect of the range of motion findings by Shaw et al. is questionable. ${ }^{34}$

There is concern that early quadriceps exercises may result in increased anterior-posterior knee laxity, resulting in damage to the graft. ${ }^{15}$ Shaw et al. concluded that the prevalence of knee instability 6 months postoperatively was reduced by performing early quadriceps exercises. ${ }^{34}$ However, Isberg et al. reported no significant difference between groups 6 months postoperatively. ${ }^{15}$ Shaw et al. incorporated a larger sample size and may be representative of the ACL injury population. ${ }^{29,34} \mathrm{~A}$ more notable finding was that A-P laxity was not different between the intervention and control groups in the long term. ${ }^{34}$ This may indicate that early quadriceps exercises can be considered safe in this population as they did not compromise stability.

\section{Limitations}

In this review, only studies reported in the English language were considered eligible due to time and resource constraints. In the case of uncertainty regarding information presented in the studies, authors were contacted via e-mail. However, if they did not reply, contact was not made telephonically due to resource constraints. Heterogeneity of the data of eligible studies did not allow for a meta-analysis to be conducted.

\section{Conclusion}

Early quadriceps exercises do not compromise the integrity of the graft, as they do not increase ligament laxity. However, it appears that the gains when performing early quadriceps exercises or restricting quadriceps exercise training to only isometric quadriceps exercises with respect to range of motion and function are small or insignificant. Further research is required and should include standardised interventions, measurement time frames and outcome measurement tools to allow for meta-analysis of the data.

\section{REFERENCES}

1. Andersson C, Odensten M, Good L, Gillquist J. Surgical or non-surgical treatment of acute rupture of the anterior cruciate ligament. J Bone Joint Surg 1989; 71(7): 965-74

2. Andersson C, Odensten M, Gillquist J. Knee function after surgical or non-surgical treatment of acute rupture of the anterior cruciate ligament: a randomized study with a long-term follow-up period. Clin Orthop Relat Res 1991; 264: 255-63.

3. Bajaj P, Arendt-Nielsen L, Andersen OK. Facilitation and inhibition of withdrawal reflexes following repetitive stimulation: electro- and psychophysiological evidence for activation of noxious inhibitory controls in humans. Eur J Pain 2004; 9 (1): 25-31.

4. Beck PR, Nho SJ, Balin J, et al. Post operative pain management after anterior cruciate ligament reconstruction. J Knee Surg 2004; 17: 18-23.

5. Beynnon BD, Uh BS, Johnson JR, et al. Rehabilitation after anterior cruciate ligament reconstruction. A prospective, randomized double-blind comparison of programs administered over 2 different time intervals. Am J Sport Med 2005; 33: 347-59.

6. Boden BP, Dean GS, Feagin JA Jr, Garrett WE Jr. Mechanisms of anterio cruciate ligament injury. Orthopedics 2000; 23: 573-8.

7. Dodd KJ, Shields N. A Systematic review of the outcomes of cardiovascular exercise programs for people with Down Syndrome. Arch Phys Med Rehabil 2005; 86: 2051-8.

8. Fithian DC, Paxton E, Stone ML, et al. Prospective trial of a treatmen algorithm for the management of the anterior cruciate ligament-injured knee. Am J Sport Med 2005; 33(3):1

9. Fleming BC, Oksendahl H, Beynnon BD. Open- or closed-kinetic chain exercises after anterior cruciate ligament reconstruction. Exerc Sport Sci Rev 2005; 33: 134-40.

10. Frank CB, Jackson DW. Current concepts review - the science of reconstruction of the anterior cruciate ligament. J Bone Joint Surg 1997; 79: $1556-76$

11. Friemert B, Bach C, Schwarz W, Gerngross H, Schmidt. Benefits of active motion for joint position sense. Knee Surg Sports Traumatol Arthrosc 2006; 14: 564-70.

12. Gialocerkowski AE, Grimmer KA, Milanese SF, Kumar VS. Application of current research evidence to clinical physiotherapy practice. J Allied Health 2004; 33(4): 230-7.

13. Hammond R. Evaluation of physiotherapy by measuring the outcome. Physiotherapy 2000; 86: 170-2.

14. Herrington L, Fowler E. A systematic literature review to investigate if we identify those patients who can cope with anterior cruciate ligament deficiency. Knee 2006;13: 260-5

15. Isberg J, Faxén E, Brandsson S, Eriksson BI, Kärrholm J, Karlsson J. Early active extension after anterior cruciate ligament reconstruction does not result in increased laxity of the knee. Knee Surg Sports Traumato Arthrosc 2006; 14: 1108-15.

16. Keays SL, Bullock-Saxton J, Keays AC, Newcombe P. Muscle strength and function before and after anterior cruciate ligament reconstruction using semitendonosus and gracilis. Knee 2001; 8: 229-34.

17. Konishi Y, Fukubayashi T, Takeshita D. Possible mechanism of quadriceps femoris weakness in patients with ruptured anterior cruciate ligament. Med Sci Sport Exerc 2002; 34: 1414-8.

18. Kvist J. Rehabilitation following anterior cruciate ligament injury; curren recommendations for sports participation. Sports Med 2004; 34(4): 269 80.

19. Law M. Measurement in occupational therapy: scientific crieteria for evaluation. Can Journal Occup Ther 1987; 54: 133-8.

20. Levangie PK, Norkin CC. Joint Structure and Function. A Comprehensive Analysis, 3rd ed. Philadelphia: FA Davis Company, 2001: 337-350.

21. Lewek M, Rudolph K, Axe M, Snyder-Mackler L.The effect of insufficient quadriceps strength on gait after anterior cruciate ligament reconstruction. Clin Biomech 2002;17: 56-63.

22. Linko E, Harilainen A, Malmivaara A, Seitsalo S. Surgical versus conservative interventions for anterior cruciate ligament ruptures in adult: review. Cochrane Database Syst Rev 2005; Issue 2 Art. No.:CD001356 DOI:10.1002/14641858.CD001356.pub3

23. Lobbenhoffer $P$, Tscherne $H$. Rupture of the anterior cruciate ligament. Current status on treatment. Der Unfallchirurg 1993; 96(3):150-68.

24. Lloyd-Smith W. Evidence-based practice and occupational therapy. $\mathrm{Br} \mathrm{J}$ Occup Ther 1997; 60: 474-8.

25. Maher CG, Sherrington C, Herbert R, Moseley A, Elkins M. Reliability of the PEDRo scale for rating quality of randomized controlled trials. Phys Ther 2003; 83: 712-21. 
26. Milne S, Brosseau L, Robinson V, et al. Continuous passive motion following total knee arthrosplasty (Review). Cochrane Database Syst Rev 2003: Issue 2. Art no : CD004260. DOI: 10.1002/14651858 CD 004260.

27. Moore KL, Dalley AF. Clinical Oriented Anatomy, 4th ed. Philadelphia: Lippincott, Williams and Wilkins, 1999; 532.

28. Morrissey MC, Brewster CE, Shields CL jr, Brown M. The effects of electrical stimulation on the quadriceps during postoperative knee immobilization. Am J Sports Med 1985;13: 40-5.

29. Portney LG, Watkins MP. Foundations of Clinical Research: Applications to Practice, 2nd ed. New Jersey: Prentice-Hall, Inc., 2000: 35, 402-3.

30. Renstrom P, Arms SW, Stanwyck TS. Strain within the anterior cruciate ligament during hamstring and quadriceps activity. Am J Sports Med 1986; 14: 83-7.

31. Roi GS, Nanni G, Tencone F. Time to return to professional soccer matches after ACL reconstruction. Sport Sciences for Health 2006; 1: 142-5.

32. Shaw T, McEvoy M, McClelland J. An Australian survey of in-patient protocols for quadriceps exercises following anterior cruciate ligament reconstruction. J Sci Med Sport 2002; 5: 291-6.

33. Shaw T, Williams MT, Chipchase LS. A user's guide to outcome measurement following ACL reconstruction. Phys Ther Sport 2004; 5: 57-67.

34. Shaw T, Williams MT, Chipchase LS. Do early quadriceps exercises affect the outcome of $\mathrm{ACL}$ reconstruction? A randomised controlled trial. Aust $J$ Physiother 2005; 51: 9-17.

35. Tay GH, Warrier SK, Marquis G. Indirect patella fractures following ACL reconstruction: a review. Acta Orthopaedica 2006; 77: 494-500.
36. Trees AH, Howe TE, Dixon J, White L. Exercise for treating isolated anterior cruciate ligament injuries in adults. Cochrane Database Syst Rev 2005; Issue 4. Art. No: CD005316. DOI: 10.1002/14651858.CD005316.

37. Trees AH, Howe TE, Grant M, Gray HG. Exercise for treating anterior cruciate ligament injuries in combination with collateral ligament and meniscal damag of the knee in adult: review. Cochrane Database Syst Rev 2007; Issue 3. Art No.:CD005961. DOI:10.1002/14651858. CD005961. pub2

38. Tyler TF, McHugh MP, Gleim GW, Nicholas SJ. The effect of immediate weightbearing after anterior cruciate ligament reconstruction. Clin Orthop Relat Res 1998; 357: 141-8.

39. Williams GN, Barrance PJ, Snyder-Mackler L, Buchanan TS. Altered quadriceps control in people with anterior cruciate ligament deficiency. Med Sci Sports Exerc 2004; 36: 1089-97.

40. Williams GN, Buchanan TS, Barrance PJ, Axe MJ, Snyder-Mackler L. Quadriceps weakness, atrophy and activation failure in predicted noncopers after anterior cruciate ligament injury. Am J Sport Med 2005; 33 402-7.

41. Woo SL, Fow RJ, Sakane M, Livesay GA, Rudy TW, Fu FH. Biomechanics of the ACL: measurements of in situ force in the ACL and knee kinematics. Knee 1998; 5: 267-88.

42. Yamamoto $\mathrm{Y}, \mathrm{Hsu}$ WH, Woo SL, Van Scyoc AH. Knee stability and graft function after anterior cruciate ligament reconstruction: a comparison of lateral and anatomical femoral tunnel placement. Am J Sport Med 2004 32: $1825-32$

\title{
ORIGINAL RESEARCH ARTICLE
}

\section{A conservative programme for treatment of anterior knee pain in adolescents}

\author{
Jacqueline Phillips (BSc Hons Biokinetics) \\ Marius F Coetsee (PhD) \\ Department of Human Movement Science, University of Zululand, KwaDlangezwa
}

\begin{abstract}
Objective. The purpose of this study was to determine the effectiveness of a $2 \frac{1}{2}$-week conservative rehabilitation programme in addressing anterior knee pain in adolescents.

Design. Subjects were randomly allocated to a control group $(N=12)$ and an experimental group $(N=18)$. The experimental group was subjected to a $2 \frac{1}{2}$-week strength, flexibility and neuromuscular rehabilitation programme. Both groups were tested before and after the $21 / 2$ weeks and the experimental group also 1 month after the post-test.

Results. The experimental group reported significant $(p<0.01)$ improvement in pain (Visual Analogue Scale), disability (Patient-Specific Functional Scale) and condition
\end{abstract}

\section{CORRESPONDENCE:}

Professor MF Coetsee

University of Zululand

Private Bag X1001

KwaDlangezwa

3886

Tel: $2735772-6639$

E-mail: mcoetsee@absamail.co.za
(Scale for Change in Condition). The experimental group tested significantly $(p<0.01)$ better for strength (quadriceps and hamstrings), flexibility (quadriceps, hamstrings and gastrocnemius) and neuromuscular control (Willknox wobble board and Bass test of dynamic balance). The control group experienced no improvement in any of the tests.

Conclusions. The $21 / 2$-week rehabilitation programme for addressing anterior knee pain in adolescents proved to be effective. The study demonstrated good retention of improvements and even further improvement after cessation of the programme. Advantages are the short duration and the fact that patients are familiarised with a home programme which they are likely to continue with. Although not addressed in this study, literature indicates that restoration of neuromuscular control might be the main contributing factor for the success of the programme.

\section{Introduction}

Anterior knee pain is a common condition that affects a wide age range of patients. ${ }^{5}$ The condition is often self-limiting, but can take up to 2 years to resolve. ${ }^{16}$ It frequently interferes with exer- 